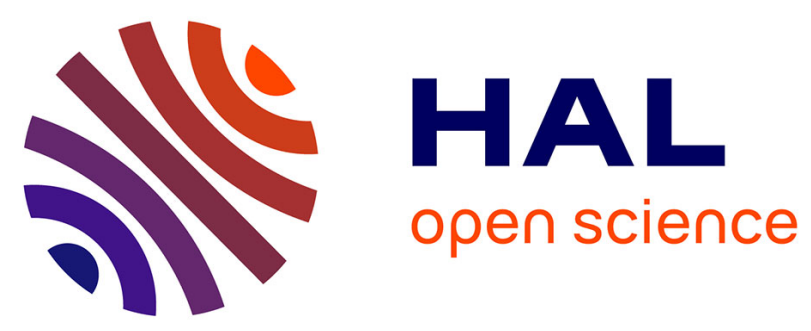

\title{
Speaking in Multiple Languages: Neural Correlates of Language Proficiency in Multilingual Word Production
}

Gerda Videsott, Bärbel Herrnberger, Klaus Hoenig, Edgar Schilly, Jo Grothe, Werner Wiater, Manfred Spitzer, Markus Kiefer

\section{- To cite this version:}

Gerda Videsott, Bärbel Herrnberger, Klaus Hoenig, Edgar Schilly, Jo Grothe, et al.. Speaking in Multiple Languages: Neural Correlates of Language Proficiency in Multilingual Word Production. Brain and Language, 2010, 113 (3), pp.103. 10.1016/j.bandl.2010.01.006 . hal-00673668

\section{HAL Id: hal-00673668 https://hal.science/hal-00673668}

Submitted on 24 Feb 2012

HAL is a multi-disciplinary open access archive for the deposit and dissemination of scientific research documents, whether they are published or not. The documents may come from teaching and research institutions in France or abroad, or from public or private research centers.
L'archive ouverte pluridisciplinaire HAL, est destinée au dépôt et à la diffusion de documents scientifiques de niveau recherche, publiés ou non, émanant des établissements d'enseignement et de recherche français ou étrangers, des laboratoires publics ou privés. 


\section{Elsevier Editorial System(tm) for Brain and Language Manuscript Draft}

Manuscript Number: BRLN-09-123R1

Title: Speaking in Multiple Languages: Neural Correlates of Language Proficiency in Multilingual Word Production

Article Type: Regular Article

Keywords: multilingualism; picture naming; word retrieval; right prefrontal cortex; functional magnetic resonance imaging

Corresponding Author: Dr. Markus Kiefer, PhD

Corresponding Author's Institution: University of Ulm

First Author: Gerda Videsott, Ph.D.

Order of Authors: Gerda Videsott, Ph.D.; Bärbel Herrnberger, Ph.D.; Klaus Hoenig, Ph.D.; Edgar Schilly; Jo Grothe; Werner Wiater, Ph.D.; Manfred Spitzer, M.D., Ph.D.; Markus Kiefer, PhD

Abstract: The human brain has the fascinating ability to represent and to process several languages. Although the first and further languages activate partially different brain networks, the linguistic factors underlying these differences in language processing have to be further specified. We investigated the neural correlates of language proficiency in a homogeneous sample of multilingual native Ladin speakers from a mountain valley in South Tyrol, Italy, who speak Italian as second language at a high level, and English at an intermediate level. In a constrained word production task under functional magnetic resonance imaging (fMRI), participants had to name pictures of objects in Ladin, Italian and English in separate blocks. Overall, multilingual word production activated a common set of brain areas dedicated to known subcomponents of picture naming. In comparison to English, the fluently spoken languages Ladin and Italian were associated with enhanced right prefrontal activity. In addition, the MR signal in right prefrontal cortex correlated with naming accuracy as a measure of language proficiency. Our results demonstrate the significance of right prefrontal areas for language proficiency. Based on the role of these areas for cognitive control, our findings suggest that right prefrontal cortex supports language proficiency by effectively supervising word retrieval. 


\title{
Speaking in Multiple Languages:
}

\section{Neural Correlates of Language Proficiency in Multilingual}

\section{Word Production}

\author{
Gerda Videsott $^{1}$, Bärbel Herrnberger ${ }^{2}$, Klaus Hoenig ${ }^{2}$, Edgar Schilly ${ }^{2,3}$, Jo Grothe ${ }^{2}$, \\ Werner Wiater ${ }^{1,4}$, Manfred Spitzer ${ }^{2,3}$ and Markus Kiefer ${ }^{2}$ \\ ${ }^{1}$ Free University of Bozen-Bolzano, Faculty of Education, Brixen-Bressanone, Italy \\ ${ }^{2}$ University of Ulm, Department of Psychiatry, Ulm, Germany \\ ${ }^{3}$ Transfer Center for Neurosciences and Learning, Ulm, Germany \\ ${ }^{4}$ University of Augsburg, Faculty of Philosophy and Social Sciences, Augsburg, Germany
}

\begin{abstract}
Brief running title: Neural correlates of language proficiency
Number of words (abstract): $\quad 199$

Number of words (main text): $\quad 7826$

Number of figures: $\quad 6$

Number of tables: 1

Number of supplementary tables 4

Keywords: multilingualism, picture naming, word retrieval, right prefrontal cortex, functional magnetic resonance imaging
\end{abstract}

Correspondence should be addressed to:

Markus Kiefer

Department of Psychiatry

Section for Cognitive Electrophysiology

University of Ulm

Leimgrubenweg 12, 89075 Ulm, Germany

Phone: +49 73150061532 Fax: +49 73150061542

E-mail: Markus.Kiefer@uni-ulm.de 


\section{Abstract}

The human brain has the fascinating ability to represent and to process several languages. Although the first and further languages activate partially different brain networks, the linguistic factors underlying these differences in language processing have to be further specified. We investigated the neural correlates of language proficiency in a homogeneous sample of multilingual native Ladin speakers from a mountain valley in South Tyrol, Italy, who speak Italian as second language at a high level, and English at an intermediate level. In a constrained word production task under functional magnetic resonance imaging (fMRI), participants had to name pictures of objects in Ladin, Italian and English in separate blocks. Overall, multilingual word production activated a common set of brain areas dedicated to known subcomponents of picture naming. In comparison to English, the fluently spoken languages Ladin and Italian were associated with enhanced right prefrontal activity. In addition, the MR signal in right prefrontal cortex correlated with naming accuracy as a measure of language proficiency. Our results demonstrate the significance of right prefrontal areas for language proficiency. Based on the role of these areas for cognitive control, our findings suggest that right prefrontal cortex supports language proficiency by effectively supervising word retrieval. 


\section{Introduction}

Proficiency in two or more languages is common in regions or countries with several native languages. How the brain subserves this fascinating ability is an important question in the neuroscience of language and increasingly relevant in intercultural and multilinguistic societies. Several neuroimaging studies have investigated the cortical representation of the first language (L1) in comparison to further languages (L2, L3, etc.) acquired at the same time, or later in life. The majority of these studies asked whether or not L1 and the further languages share the same neuronal substrate or whether each language is distinctively represented in the brain.

As languages spoken in a specific socio-cultural setting differ with regard to linguistic code (e.g., phonology, syntax), age of acquisition, intensity of exposure or speakers' proficiency (Perani et al. 1998), activation differences between L1 and further languages could depend on one or more of these linguistic factors. In fact, previous neuroimaging studies suggested an influence of these variables for the neural representation of multiple languages and particularly emphasized the role of language proficiency (for a review see Abutalebi 2008; Kotz 2009). Although a lot of progress has been made in elucidating the brain structures underlying multilingualism (Perani \& Abutalebi, 2005; Indefrey 2006; Abutalebi, 2008), the role of proficiency has to be better enlightened.

There is converging evidence that the processing of further languages (L2, L3 etc.) generally recruits the network of classical language areas in inferior frontal and temporo-parietal cortex that also subserves L1 (Indefrey 2006; Abutalebi \& Green 2007; Abutalebi 2008). While several neuroimaging studies found entirely overlapping activation patterns for the first and further 
languages in production and comprehension tasks (e.g. Illes et al. 1995; Chee et al. 1999; Hernandez et al. 2000, 2001; Rodriguez-Fornells et al. 2005), a stronger recruitment of some brain areas for the later acquired and less fluently spoken languages has been sometimes obtained. One of the most robust findings is the stronger involvement of left inferior prefrontal areas, including the inferior frontal gyrus, in the production and comprehension of languages that are spoken at a relatively low proficiency level (Indefrey 2006; Abutalebi \& Green 2007; Abutalebi 2008; Abutalebi \& Green 2008).

For instance, in free language production, Kim et al. (1997) found increased activity in left inferior frontal gyrus (IFG) for L2 when it was acquired later in life than L1. Similarly, in picture naming, stronger activation in left IFG was again found for L2, but only when subjects were less proficient than in L1 (De Bleser et al. 2003; Vingerhoets et al. 2003). In word generation, activity in left IFG decreased with increasing proficiency of L2 (Yetkin et al. 1996). Increased activity in left IFG during L2 processing was also obtained for sentence comprehension (Yokoyama et al. 2006), or processing of syntactic structure (Suh et al. 2007). As the left IFG is involved in several language tasks including phonetic, syntactic and semantic processing (Indefrey and Levelt 2000), its specific importance for processing a less fluently spoken L2 has not been unequivocally determined yet. It has been proposed that particularly the posterior portions of IFG subserve syllabification of speech which is more demanding for languages spoken at a low proficiency level (Indefrey 2006). Alternatively, Abutalebi and colleagues (Abutalebi \& Green 2007; Abutalebi 2008; Abutalebi \& Green 2008) proposed in their language control theory of bi- und multilingualism that enhanced left inferior prefrontal activation for low proficient languages reflects the increased demands on cognitive control processes. As prefrontal 
activation for low proficient languages was frequently observed outside the classical frontal language area (e.g., Broca's area) and encompassed regions typically involved in cognitive control and conflict resolution (Carter et al., 1998; Kiefer et al., 2005a), Abutalebi and colleagues assume that at lower levels of language proficiency word retrieval is more effortful due to a strong lexical competition between languages (Abutalebi et al. 2008). This competition between languages is resolved with the intervention of left prefrontal circuits supporting cognitive control.

In addition to left prefrontal cortex, there are preliminary reports suggesting that word production in languages spoken at a high proficiency might depend on neural circuits in right prefrontal areas (Calabrese et al. 2001; Vingerhoets et al. 2003). As right prefrontal cortex plays an important role in action control during response inhibition (de Zubicaray et al., 2000; Garavan et al. 2002; Rubia et al. 2003) and during memory retrieval (Tulving 1999; Vallesi and Shallice 2006), enhanced activity in this region might reflect efficient control processes that support successful word production (Abutalebi \& Green 2007; Abutalebi 2008). As previous evidence for the role of right prefrontal cortex in high language proficiency was only tentative, the neural correlates of proficiency in multilingual language production deserve further systematic investigation.

Figure 1 about here

The present fMRI study therefore investigated the effects of language proficiency on the neural substrate of word production in multiple languages within a unique homogenous multilingual 
group of participants who grew up in the same social context and used their different languages in a comparable manner. Our participants were native Ladin speakers from South Tyrol in Italy who live in a circumscribed area of the Badia Valley in the Dolomites mountain range close to the border to Austria (see Figure 1). Their first language Ladin (L1) is a Roman Language that is spoken by a population of about 30,000 individuals, particularly in the rural villages of the Dolomites mountain valleys. Typically, during their school career, native Ladin speaking children start to learn Italian as the first second language (L2) at an age of four to five, and German as their next second language (L3) at an age of six to seven. Both Italian and German are acquired at a similar age and spoken with a proficiency similar to Ladin. At an age of thirteen to fourteen English (L4) is acquired but less practiced and mostly performed at an intermediate proficiency level. Hence, this specific participant population is ideally suited to address differential language proficiency within the same subjects: We assessed word production in highly proficient Ladin (L1) and Italian (L2) as well as in low proficient English (L4). German (L3) was not investigated because its proficiency level is comparable with Italian.

We used a picture naming task to study multilingual word production, because the processes underlying task performance are well defined and highly controllable within an experiment (Humphreys et al. 1988; Levelt et al. 1999). It is generally accepted that picture naming encompasses the following stages: (i) perceptual encoding of the picture, (ii) semantic analysis and object recognition, (iii) retrieval and selection of the word form, (iv) phonological encoding, and finally (v) articulation. As sentences and discourses at the intermediate and higher levels of language, respectively, are composed of words as elementary units, language proficiency can be addressed already at this elementary level. 
We expect that picture naming in Ladin, Italian and English recruits a neural network known to be involved in perceptual, semantic and language processing. Based on previous findings of a left IFG recruitment in languages spoken at a low proficiency level, English (L4) as the least fluent language is expected to activate left IFG more strongly than native Ladin (L1) and highly proficient Italian (L2). Previous preliminary findings are suggestive of an involvement of right prefrontal cortex in high language proficiency, presumably due to its general role in cognitive and language control. We therefore predict that the highly proficient languages Ladin and Italian activate right prefrontal cortex more strongly than English. Hence, low and high language proficiency in multiple languages should depend on partially dissociable neural pathways.

\section{Materials and Methods}

Subjects. 20 healthy right-handed (Oldfield 1971) multilingual volunteers (11 females, 9 males; mean age $=27.3$ years, range $=20-35$ years $)$ with normal or corrected to normal visual acuity and no neurological or psychiatric disorders participated in the fMRI study after giving written informed consent. The study was conducted in accordance with the Declaration of Helsinki and approved by the local Ethical Committee. Subjects were paid for their participation. All participants were native Ladin speakers from the Badia mountain valley in South Tyrol, Italy (402 km²; about 10,000 inhabitants). They spent their early childhood in an almost exclusively Ladin environment and grew up in the same socio-cultural environment with both parents being Ladin speakers. Many participants were also relatives. All participants have the certificate of the Autonomous Province of Bozen-Bolzano that classifies their language competence in Ladin, 
Italian and German at the highest proficiency level A (16 participants) or second highest level B (4 participants). Due to a lack of objective language proficiency tests that allow for comparing competence in the four languages at a common scale, we had to rely on an in-house questionnaire, with which we assessed history of language acquisition and proficiency. All participants had a similar order and age of language acquisition (Ladin: 0 years; Italian: 5 years; German: $\sim 7$ years and English: $\sim 14$ years) and a similar language use and exposure (mostly Ladin, then Italian, then German and then English). Proficiency ratings in language production on a ten-point scale (lowest proficiency $=1$, highest proficiency $=10$ ) revealed highest for proficiency for Ladin in comparison to the other languages $(\mathrm{t}(19)>3.52, \mathrm{p}<.01)$, similar high proficiency for Italian and German $(\mathrm{t}(19)<.26, \mathrm{p}>.80)$ and lowest proficiency for English in comparison to the other languages $(\mathrm{t}(19)>7.01, \mathrm{p}<.0001)$ : Ladin $=9.6$, SD .94; Italian $=8.4$, SD .82; German $=8.3$, SD 1.05; English $=4.7$, SD 1.96). During their early childhood, all subjects spoke almost exclusively Ladin at home and with their friends with only a predominantely passive competence of Italian and German through mass media and tourism. At primary school, they all attended the same paritetic school model (instructions half in Italian and half in German with Ladin as a support language) and had the same language curriculum. With respect to the Common European Framework of Reference for Languages, participants' proficiency level for second and further languages was highest for Italian (range C1-C2) and German (range B2-C1-C2) and lowest for English (range B1-B2-C1-C2).

Materials. The stimulus material for the picture naming task consisted of a well-matched picture set of 144 color pictures, 48 per language (Ladin, Italian, English) depicting common objects from a variety of categories in a canonical view. The pictures were selected on the basis of 
existing standardized picture sets (Snodgrass and Vanderwart 1980, Berman et al. 1989, Cycowicz et al. 1997, and the "International Picture Naming Project" of the CRL, University of California/San Diego, http://crl.ucsd.edu/ aszekely/ipnp/) on the principle that stimulus objects should unequivocally express a lexical concept (Indefrey and Levelt 2000), reducing subjective interpretations as much as possible and admitting only one precise and well-defined answer as word output. In order to avoid repetition effects (Kiefer 2005b), object pictures were presented only once in the experiment and hence were not repeated as stimulus in another language. An initial set of 400 pictures was tested in a pilot study in order to match the final pictures for the different languages in several important variables which are known to influence naming performance. In the pilot study, 20 participants from the Badia Valley different from the participants in the main experiment were asked first to name the picture and second to rate the familiarity and visual complexity of the objects on six-point scales $($ minimum $=1 /$ maximum $=$ 6). Hereby, the material was matched for name agreement $(F(2,147)=.81, p>.44)$, word length $(\mathrm{F}(2,147)=0, \mathrm{p}=1$, familiarity $(\mathrm{F}(2,147)=2.42, \mathrm{p}>.07)$ and visual complexity $(\mathrm{F}(2,147)=1.2$ p >.31) across a) standard Ladin of Badia Valley, b) standard Italian, and c) standard British English.

Procedure. The object pictures were presented visually with Presentation® (Neurobehavioral Systems, Inc. Albany, CA, U.S.A.) in separate sessions for each language (Ladin, Italian, and English). The required language was indicated at the beginning of the session. Picture naming in one of the three languages was assigned to separate sessions in order to minimize effects of language switching, which were not of theoretical interest. Within each session, active blocks, in which pictures had to be named in a specified language, were alternated with fixation blocks, in 
which only a fixation cross was shown. Each block had a duration of $24 \mathrm{~s}$ and comprised six picture naming trials. One trial of an active block first showed a fixation cross for $600 \mathrm{~ms}$, then an object picture for $500 \mathrm{~ms}$. After a pseudo-randomly drawn interstimulus interval of 2600 , 2900 or $3200 \mathrm{~ms}$ showing a fixation cross, the next trial started. Each scanning session consisted of 9 fixation blocks and 8 active blocks. Sessions started and ended with a fixation block. There was a break of 3 min. between scanning sessions. Two different sequences of active blocks were created and each of them assigned to half of the participant group. The order of the language sessions (Ladin, Italian and English) were individually randomized for each participant in order to control for sequence effects. Each session started with training trials similar to the one used in the main experiment so that subjects could adapt to the new language. Prior to the scanning sessions, subjects were instructed to spontaneously name the object without article or adjectives in the required language as fast and as accurately as possible by using the first name which came to their mind. Furthermore, they were trained to name the object at the basic level of abstraction (e.g., "dog", "table") using ten pictures not shown in the main experiment. Subjects were told that they were neither required to name the object at a subordinate (e.g. "poodle"), nor at a superordinate level (e.g. "animal", "furniture"). All instructions before and during fMRI scanning were given in Ladin. The produced names were digitally recorded and stored to disk. From these recordings, the background noise from the scanner was removed by digital filtering in order to obtain the undistorted naming response. In the analysis of naming performance appropriate names (including synonyms) at the basic or subordinate level were treated as correct responses, whereas inappropriate names as well as superordinate names were treated as errors. 
MR scanning and data analysis. Functional and structural MR images were recorded with a 3 Tesla Allegra MRI system (Siemens, Erlangen, Germany). For the functional scans, a T2*_ weighted single-shot gradient-echo EPI sequence $\left(\mathrm{TE}=38 \mathrm{~ms}, \mathrm{TR}=2000 \mathrm{~ms}\right.$, flip angle $=90^{\circ}$, matrix $64 \times 64$ pixels, field of view (FOV) $210 \times 210 \mathrm{~mm}^{2}$, voxel size $3.3 \times 3.3 \times 4.9 \mathrm{~mm}^{3}$ ) was used. Starting from the bottom of the brain, 30 transversal slices were acquired in interleaved order. Slice orientation was parallel to a line connecting the bases of the frontal lobe and the cerebellum. The entire fMRI experiment consisted of three imaging sessions (Ladin, Italian, English) of about 7 minutes each, resulting in a total of 618 functional volumes. Structural images were acquired with a T1-weighted MPRAGE sequence $(\mathrm{TR}=2300 \mathrm{~ms}, \mathrm{TE}=3.9 \mathrm{~ms}$, flip angle $=12^{\circ}$, matrix $256 \times 256$ pixels, FOV $=256 \times 256 \mathrm{~mm}^{2}$, voxel size $1 \times 1 \times 1 \mathrm{~mm}^{3}$ ) Functional data were preprocessed and statistically analyzed with SPM5 (http://www.fil.ion.ucl.ac.uk/spm/software/spm5). Preprocessing included correction for differences in slice-timing, spatial realignment to the first volume of the first session, normalization to the MNI reference brain (re-sampled to a voxel size of $2 \times 2 \times 2 \mathrm{~mm}^{3}$, and smoothing with an isotropic Gaussian kernel of $8 \mathrm{~mm}$ FWHM.

Statistical analysis used a hierarchical random-effects model with two levels. At the first level, single-subject fMRI responses were modelled within a block design where the design matrix had volumes of the picture naming blocks coded with one and zero otherwise, convolved with the canonical hemodynamic response function. The fixation blocks served as an implicit baseline. A temporal high-pass filter with cutoff frequency $1 / 128 \mathrm{~Hz}$ was used in order to remove physiological noise, and temporal autocorrelation in the fMRI time series was estimated and corrected for using a first-order autoregressive model. For each subject, the main effect of picture 
naming ( $\mathrm{L} 1+\mathrm{L} 2+\mathrm{L} 4>$ baseline) as well as the pairwise contrasts between languages were determined.

To allow for inferences at the population level, second level analyses treated subjects as a random effect and tested all first level contrasts in separate one-sample t-tests against zero. In a separate correlation analysis, accuracy in the picture naming task as a performance measure of proficiency, self-rated proficiency and age of language acquisition were entered as regressors in the different language conditions, leading to three correlation coefficients per language. The main effect of picture naming was thresholded at $\mathrm{p}<.001$ (corrected for multiple comparisons across the entire brain). The pairwise contrasts between languages and the correlation analyses were thresholded at a significance level of $\mathrm{p}<.001$ (uncorrected). Given that conjunction analyses are more conservative, commonalities between language contrasts (L1-L4 and L2-L4) were assessed at $\mathrm{p}<.005$ (uncorrected).

\section{Results}

Behavioral data. We assessed picture naming performance in Ladin, Italian, and English by determining accuracy of the produced object names. A repeated measures analysis of variance (ANOVA) revealed that naming accuracy significantly varied between languages $(\mathrm{F}(2,38)=$ 9.112, $\mathrm{p}<.001)$ : Accuracy was highest for the first language Ladin (89\%, SD 6.5) and for the second language Italian, which was acquired early in life (86\%, SD 7.4). Accuracy was worst in English, which was acquired during puberty (79\%, SD 11.6). Least significant differences (LSD) post-hoc tests showed that accuracy in Ladin and Italian was significantly higher than in English 
(all ps < .004). In contrast, accuracy in Ladin and Italian did not differ from each other significantly $(\mathrm{p}>.30)$.

Figure 2 about here

\section{fMRI data}

Network of picture naming. When the MR signal to all three languages (Ladin, Italian and English) was compared with the fixation baseline condition, brain areas dedicated to known subcomponents of picture naming were identified (Figure 2 and Supplementary Table 1). (i) Occipital and inferior temporal areas are involved in visual perceptual processing and object recognition. (ii) The hippocampus contributes to memory retrieval. (iii) The inferior frontal gyrus and adjacent insula are involved in articulatory speech planning while neighboring prefrontal areas and the anterior cingulate gyrus are associated with cognitive control processes. (iv) Precentral gyrus, supplementary motor area and cerebellum reflect motor processes during articulation. We also compared the MR signal in each language with the baseline condition. This analysis revealed that picture naming in Ladin, Italian and English largely activated the same set of brain areas (Supplementary Tables 2-4).

Figures 3, 4 and 5 and Table 1 about here

Differences between languages. Contrasting the fluently spoken languages Ladin (L1) and Italian (L2) with English (L4), which is spoken at an intermediate level, reveals the brain 
network that supports high language proficiency (L1-L4, L2-L4). The reversed comparisons yield brain areas more strongly recruited in a less fluently spoken language (L4-L1, L4-L2). High language proficiency was associated with enhanced activity in right prefrontal areas (Figure 3 and Table 1). Native Ladin elicited higher activity than less fluent English (L1-L4) in the right anterior (orbital superior frontal gyrus, BA 11) and dorsolateral (middle frontal gyrus, BA 46/BA 10) prefrontal cortices (Figure 3A). Similarly, highly fluent Italian (Figure 3B) elicited higher activity than English (L2-L4) in the right dorsolateral (middle frontal gyrus, BA 46) and inferior (inferior frontal gyrus, BA 47) prefrontal cortices as well as in the right insula (BA 47). Figure 4 demonstrates that clusters activated to Ladin and Italian, respectively, considerably overlapped in right prefrontal areas. In a conjunction analysis, we determined brain areas that showed stronger activation for both Ladin and Italian in comparison to English (L1-L4 and L2-L4). This analysis revealed the right dorsolateral prefrontal cortex (middle frontal gyrus, BA 46/BA 10) as the region common to both highly proficient languages in comparison to least proficient English (Figure 3C). As shown in Figure 5, right prefrontal cortex was generally deactivated in comparison to the resting state baseline condition, but showed more activation (i.e. was less deactivated) for the highly proficient languages $(\mathrm{L} 1, \mathrm{~L} 2)$ than for $\mathrm{L} 4$.

Figure 6 about here

Reversed contrasts demonstrated that least proficient English elicited a higher MR signal than Ladin (L4-L1) in the left inferior frontal gyrus (BA 44/BA 6) and in the cerebellum, and a higher signal than Italian (L4-L2) in the cerebellum only (Figure 6 and Table 1). Italian showed greater 
activity than Ladin (L2-L1) in the right middle temporal gyrus. The opposite contrast (L1-L2) did not yield any significant differences.

Correlation analysis. We investigated the relation between the fMRI signal and linguistic variables as well as proficiency measures of the multilingual participant group. Accuracy in the picture naming task as a performance measure of proficiency, self-rated proficiency and age of language acquisition were entered as regressors in these analyses. Significant correlations were obtained for naming accuracy as regressor. With English as the language with highest subject variability in naming accuracy, we found a correlation between the MR signal and naming accuracy in the right dorsolateral prefrontal cortex (Figure 3D) encompassing the middle frontal gyrus (BA 46). For Italian, the MR signal in the same region was also found to correlate with naming performance but at a lower significance level $\mathrm{p}<.005$, presumably due to smaller subject variance (see the behavioral data section). For Ladin, with the lowest interindividual variability, we did not find a significant correlation. None of the other variables showed any significant relation to brain activity even at $\mathrm{p}<.005$.

\section{Discussion}

In a picture naming task, we investigated the neural correlates of multilingual word production within a unique homogeneous participant group of native Ladin speakers from the Badia mountain valley in South Tyrol, Italy. Their exceptional language abilities allow us to study, in the same subject, the brain areas involved in word production at high and low proficiency levels. Our subjects acquired fluent Italian as their first foreign language early in their school career and English as their last and least proficient foreign language in puberty. Sequence of language 
acquisition as well as exposure to the different languages was hence quite comparable in all participants. Furthermore, the well-controllable picture naming task is ideally suited to investigate language production processes at the word level. Given this unique multilingual sample and the constrained language production task, our study provides significant evidence regarding the network of brain areas involved in word production at high and low proficiency levels.

Picture naming in the three languages (Ladin, Italian and English) generally recruited brain areas dedicated to perceptual, semantic and language-related processes. Most importantly, differences in the MR signal between languages were observed, which were related to proficiency. As these language-related differences were found outside the classical language areas mainly in prefrontal regions dedicated to cognitive control, our data suggest that speaking in multiple languages differ with regard to processing demands, but not with regard to the neural representation of languages per se. We found that the least fluently spoken language English activated left inferior frontal gyrus (IFG) and the cerebellum more strongly than the native language Ladin (L4-L1). The cerebellum was also more strongly activated in comparison to Italian (L4-L2). In contrast, the fluently spoken languages Ladin and Italian recruited right prefrontal areas more strongly than English (L1-L4, L2-L4). This area appears to play a particular role in high language proficiency because activity was functionally related to naming performance: The MR signal in right prefrontal cortex positively correlated with naming accuracy in English and Italian. Hence, we showed for the first time that right prefrontal cortex is involved in processes underlying proficiency irrespective of the language in question. In the following, we first discuss the brain 
network generally involved in picture naming before we move on to functional activation differences related to language proficiency.

\section{Brain network of multilingual picture naming}

Multilingual picture naming generally activated a large network of brain areas that are typically involved in visual perceptual, semantic, and word generation tasks. The bilateral activation of the occipital lobe and neighboring inferior temporal areas reflects visual perceptual processing during object recognition (Vandenberghe et al. 1996; Bly and Kosslyn 1997). Activity in the hippocampus indexes long-term memory processes (Fernández et al. 1999 Nobre and McCarthy 1995) presumably subserving word retrieval. Activity in middle temporal cortex has been associated with lexical retrieval and lexical-semantic processing (Indefrey and Level 2000). Picture naming also elicited widespread activity in left frontal areas including the inferior frontal gyrus, the adjacent insula and the anterior cingulate cortex. A part of inferior frontal gyrus (BA 44, Broca's area) has been related to articulatory speech planning (Indefrey and Level 2000). However, the observed activity in left frontal regions was quite extended (BA 44, BA 47, BA 48) and also encompassed medial prefrontal areas (e.g., anterior cingulate gyrus, BA 32) typically involved in executive control and response monitoring (Norman and Shallice 1986; Posner and DiGirolamo 1998). Therefore, prefrontal activity during multilingual word production has been assumed to index language control processes (Abutalebi \& Green 2007; Abutalebi 2008; Abutalebi \& Green 2008). Activity in the precentral gyrus, the supplementary motor area and the cerebellum might reflect the execution of the articulatory motor program (Paulesu 1993; Crinion et al. 2006). In addition to this distributed network underlying word production in general, 
several brain areas showed differential activation between languages thereby forming neural signatures of proficiency.

\section{Brain activity related to low language proficiency}

English (L4) as the least proficient language recruited the cerebellum more strongly in comparison to Ladin (L1) and Italian (L2). Similarly, activation of the cerebellum in response to English as the first foreign language was also observed in bilingual Japanese participants (Yokoyama et al. 2006). As the cerebellum plays an important role in articulation-related motor processes (Ackermann et al. 1998; Silveri and Misciagna 2000), increased activity may reflect the larger demands on motor planning in a language at a low proficiency level. English also elicited stronger activity in the left inferior frontal gyrus (IFG) in comparison to the first language Ladin. Stronger activity of left inferior frontal areas including the IFG in low proficient speakers of a given language is one of the most robust findings in the research of bi- and multilingualism (Indefrey 2006; Rodriguez-Fornells et al. 2005; Abutalebi \& Green 2007; Abutalebi 2008; Abutalebi \& Green 2008). IFG activity seems to reflect varying levels of proficiency and/or age of acquisition rather than intrinsic differences between L1 and further languages: Increased activity of left IFG was also observed for words of the first language, which are learned later in life (Fiebach et al. 2003) and for late learners of a second language in comparison to early learners (Hernandez et al. 2007). As age of language acquisition, language exposure and proficiency are correlated (Indefrey 2006), it is difficult to differentiate between these variables. Although there is a general agreement that increased left inferior frontal activity to low levels of language proficiency reflects the higher processing demands, the precise role of this brain area for multilingualism has been a matter of debate. Indefrey (2006) suggests that left 
IFG is engaged in postlexical syllabification processing during word production. He proposes that this process in the IFG is optimized for early acquired languages and thus less efficient for later acquired and less fluent languages. For that reason, activity of this region is enhanced when a word has to be pronounced in a language spoken at a low proficiency level. Alternatively, Abutalebi and colleagues (Abutalebi \& Green 2007; Abutalebi 2008; Abutalebi \& Green 2008) propose that left inferior prefrontal cortex resolves competition and conflict between languages in congruency with its general role in action control and executive function. According to this language control theory of bi- and multilingualism, speakers who are low proficient in a given language (e.g., L2) receive strong competition from a more fluent language (e.g., L1) thereby increasing the demands on control processes subserved by left prefrontal regions. In line with this interpretation, we found increased left inferior frontal activity in comparison to L1 Ladin only for the least fluent English (L4), but not for the highly fluent Italian (L2). Furthermore, peak activation was dorsal to the classical anterior language area. Presumably, language conflict is highest for English due to the conjoint competitive influence from the other three languages spoken at a high proficiency level.

\section{Brain activity related to high language proficiency}

Picture naming in the fluently spoken languages Ladin and Italian (L1, L2) elicited enhanced activity in right prefrontal areas in comparison to English (L4). Activation clusters for Ladin and Italian were not entirely identical, but highly overlapping. They encompassed right dorsolateraland ventrolateral (Ladin and Italian) as well as anterior prefrontal areas (Ladin only). All word production tasks were associated with a relative deactivation in comparison to the resting state baseline, presumably because in the resting condition subjects were engaged in thinking of past 
events, which highly involves right prefrontal cortex (e.g., Binder et al., 1999; see also Schafer \& Constable 2009). However, proficient languages Ladin and Italian showed more activation (i.e. less deactivation) than the least proficient language English. Given that right prefrontal activity was obtained for the fluently spoken languages, our data suggest that proficiency in word production depends on neural circuits in this area. This interpretation is further supported by the correlation analysis: The MR signal in right dorsolateral prefrontal cortex (middle frontal gyrus) specifically correlated with naming accuracy as a measure of language proficiency. Other variables, such as age of language acquisition, did not modulate the MR signal. It should also be noted that the correlation between naming accuracy and brain activity was present for both English and Italian. In fact, it was more pronounced for English than for Italian, presumably because performance in Italian was more homogenous and relatively close to ceiling. In line with preliminary earlier data (Calabrese et al. 2001; Vingerhoets et al. 2003), our results suggest that activity in right prefrontal areas supports successful word production and is related to interindividual differences in proficiency irrespective of the language under investigation. Most importantly, right prefrontal activity was apparent both between languages (contrast of Italian or Ladin to English) and within a language (correlation of naming accuracy and MR signal for English and Italian). Right prefrontal activity therefore most likely relates to language proficiency rather than to any intrinsic aspects of a language or the age of language acquisition.

The present fMRI data, of course, do not allow deciding whether activity in right prefrontal areas is a cause or an effect of language proficiency. In addition, the precise functional role of right prefrontal cortex in language proficiency has to be further specified in future work. Previous neuroimaging studies suggest that right prefrontal cortex supports cognitive control and 
monitoring processes. For instance, several studies associated right prefrontal cortex with monitoring during episodic memory retrieval (Fletcher and Dolan 1999; Henson et al. 1999; Allan et al. 2000; Grady et al. 2001; Ranganath et al. 2007): Right prefrontal cortex is thought to support memory retrieval through evaluating whether the retrieved information belongs to the intended target episode or not. Right prefrontal cortex has also been shown to be active during cognitive control processes that require the inhibition of unintended response tendencies (de Zubicaray et al., 2000; Garavan et al. 2002; Rubia et al. 2003). In particular, right prefrontal cortex activity was increased when inhibitory control of prepotent response tendencies was successful (Rubia et al., 2003). According to the language control theory of multilingualism (Abutalebi \& Green 2007; Abutalebi 2008; Abutalebi \& Green 2008), cognitive control is necessary to resolve conflict and competition between languages thereby supporting language proficiency. Presumably, neural circuits in right prefrontal cortex foster word retrieval by monitoring and controlling the eligibility of competing object names. Hence, high language proficiency may depend on efficient cognitive control as indicated by the presently observed increased activity in right prefrontal areas. The interesting question arises whether explicitly training language proficiency enhances activity in right prefrontal areas during word production. This would further substantiate the role of right prefrontal cortex for proficiency in multilingual word production.

We are aware that our study only captures fluency of word production as one out of many aspects of language proficiency. Of course, language proficiency is a much more complex construct and also comprises syntactic, phonetic and pragmatic competence during both language production and comprehension. These heterogeneous aspects cannot be assessed within one 
study and were also beyond the scope of this work. However, larger linguistic units such as sentences and discourses necessarily build upon words so that findings from word production studies are relevant for these higher levels of language proficiency. Furthermore, we believe that our strategy of investigating a highly homogenous multilingual participant group with respect to linguistic and socio-cultural variables within a cognitively well-defined language paradigm could also be a promising approach for studying language proficiency at higher levels of complexity.

In conclusion, the present study relates high language proficiency to activity in right prefrontal areas. As right prefrontal activity was observed for two fluently spoken languages (L1, L2) and was functionally related to interindividual differences in language proficiency within languages (L2, L4), it is unlikely that it is contingent to intrinsic linguistic aspects of the languages or the age of language acquisition. Our results therefore suggest that the differential activation of right prefrontal cortex does not reflect differences in language representation per se, but rather differences in higher-level cognitive processing associated with language use. Based on the known functionality of right prefrontal cortex, we propose that proficiency in multilingual word production depends on efficient cognitive control processes (Abutalebi \& Green 2007; Abutalebi 2008). 


\section{Acknowledgements}

This work was supported by an award from the Association L. Heilmann to G.V. and by a grant from the German Research Foundation (DFG Ki 804/5-1) to M.K.. The authors thank Gerwin Müller for his help with data acquisition and two anonymous reviewers for their helpful comments. 


\section{References}

Abutalebi, J. (2008). Neural aspects of second language representation and language control. Acta Psychologica, 128, 466-478.

Abutalebi, J., \& Green, D. (2007). Bilingual language production: The neurocognition of language representation and control. Journal of Neurolinguistics, 20, 242-275.

Abutalebi, J., \& Green, D. W. (2008). Control mechanisms in bilingual language production: Neural evidence from language switching studies. Language and Cognitive Processes, $23,557-582$.

Abutalebi, J., Annoni, J. M., Zimine, I., Pegna, A. J., Seghier, M. L., Lee-Jahnke, H., Lazeyras, F., Cappa, S. F., \& Khateb, A. (2008). Language control and lexical competition in bilinguals: An event-related FMRI study. Cerebral Cortex, 18, 1496-1505.

Ackermann, H., Wildgruber, D., Daum, I. \& Grodd, W. (1998). Does the cerebellum contribute to cognitive aspects of speech production? A functional magnetic resonance imaging (fMRI) study in humans. Neuroscience Letters, 247, 187-90.

Allan, K., Dolan, R.J., Fletcher, P.C. \& Rugg, M.D. (2000). The role of the right anterior prefrontal cortex in episodic retrieval. NeuroImage, 11, 217-227.

Berman, S., Friedman, D. \& Hamberger, M. (1989). Developmental picture norms: Relationships between name agreement, familiarity, and visual complexity for child and adult ratings of two sets of line drawings. Behavior Research Methods, Instruments, \& Computers, 21, 371-382. 
Binder, J. R., Frost, J. A., Hammeke, T. A., Bellgowan, P. S. F., Rao, S. M., \& Cox, R. W. (1999). Conceptual processing during the conscious resting state: A functional MRI study. Journal of Cognitive Neuroscience, 11, 80-93.

Binder, J.R., Frost, J.A., Hammeke, T.A., Cox, R.W., Rao, S.M. \& Prieto, T. (1997). Human brain language areas identified by functional magnetic resonance imaging. Journal of Neuroscience, 17, 353-362.

Bly, B.M. \& Kosslyn, S.M. (1997). Functional anatomy of object recognition in humans: Evidence from positron emission tomography and functional magnetic resonance imaging. Current Opinion in Neurology, 10, 5-9.

Calabrese, P., Neufeld, H., Falk, A., Markowitsch, H.J., Müller, C., Heuser, L., Gehlen, W. \& Durwen, H.F. (2001). Wortgenerierung bei Bilingualen - eine fMRT-Studie mit Implikationen für Sprach- und Gedächtnisprozesse. Fortschritte der Neurologie Psychiatrie, 69, 42-50.

Carter, C. S., Braver, T. S., Barch, D. M., Botvinick, M. M., Noll, D., \& Cohen, J. D. (1998). Anterior cingulate cortex, error detection, and the online monitoring of performance. Science, 280, 747-749.

Chee, M.W., Caplan, D., Soon, C.S., Sriram, N., Tan, E.W., Thiel, T. \& Weekes, B. (1999). Processing of visually presented sentences in Mandarin and English studied with fMRI. Neuron, 23, 127-137.

Chee, W.L., Weekes, B., Lee, K.M., Soon, C.S., Schreiber, A., Hoon, J.J. \& Chee, M. (2000). Overlap and dissociation of semantic processing of Chinese characters, English words and pictures: Evidence from fMRI. NeuroImage, 12, 392-403. 
Crinion, J., Turner, R., Grogan, A., Hanakawa, T., Noppeney, U., Devlin, J.T., Aso, T., Urayama, S., Fukuyama, H., Stockton, K., Usui, K., Green, D.W. \& Price, C.J. (2006). Language control in the bilingual brain. Science, 312, 1537-40.

Cycowicz, Y.M., Friedman, D., Rothstein, M. \& Snodgrass, J.G. (1997). Picture naming by young children: Norms for name agreement, familiarity, and visual complexity. Journal of Experimental Child Psychology, 65, 171-237.

De Bleser, R., Dupont, P., Postler, J., Bormans, G., Speelman, D., Mortelmans, L. \& Debrock, M. (2003). The organisation of the bilingual lexicon: a PET study. Journal of Neurolinguistics, 16, 439-456.

de Zubicaray, G. I., Andrew, C., Zelaya, F. O., Williams, S. C., \& Dumanoir, C. (2000). Motor response suppression and the prepotent tendency to respond: A parametric fMRI study. Neuropsychologia, 38, 1280-1291.

Dehaene, S., Dupoux, E., Mehler, J., Cohen, L., Paulesu, E., Perani, D., Van Moortele, P.F., Lehéricy, S. \& Le Bihan, D. (1997). Anatomical variability in the cortical representation of first and second language. Neuroreport, 8, 3809-3815.

Embick, D., Marantz, A., Miyashita, Y., O’Neil, W. \& Sakai, K.L. (2000). A syntactic specialization for Broca's area. Proceedings of the National Academy of Sciences of the United States of America, 97, 6150-6154.

Fernández, G., Effern, A., Grunwald, T., Pezer, N., Lehnertz, K., Dumpelmann, M., Van Roost, D. \& Elger, C.E. (1999). Real-time tracking of memory formation in the human rhinal cortex and hippocampus. Science, 285, 1582-1585. 
Fiebach, J.F., Friederici, A.D., Müller, K., von Cramon, D.Y. \& Hernandez, A.E. (2003). Distinct brain representations for early and late learned words. NeuroImage, 19:16271637.

Fletcher, P.C. \& Dolan, R.J. (1999). Right prefrontal cortex responds to item familiarity during a memory encoding task. Memory, 7, 703-713.

Garavan, H., Ross, T. J., Murphy, K., Roche, R. A., \& Stein, E. A. (2002). Dissociable executive functions in the dynamic control of behavior: Inhibition, error detection, and correction. NeuroImage, 17, 1820-1829.

Grady, C.L., McIntosh, A.R., Beig, S. \& Craik, F.I. (2001). An examination of the effects of stimulus type, encoding task, and functional connectivity on the role of right prefrontal cortex in recognition memory. NeuroImage, 14, 556-571.

Hashimoto, R. \& Sakai, K. (2002). Specialization in the left prefrontal cortex for sentence comprehension. Neuron, 35, 589-597.

Heim, S., Alter, K., Ischebeck, A.K., Amunts, K., Eickhoff, S.B., Mohlberg, H., Zilles, K., Von Cramon, D.Y. \& Friederici, A.D. (2005). The role of the left Brodmann's areas 44 and 45 in reading words and pseudowords. Cognitive Brain Research, 25, 982-93.

Henson, R.N., Shallice, T. \& Dolan, R.J. (1999). Right prefrontal cortex and episodic memory retrieval: A functional MRI test of the monitoring hypothesis. Brain, 122, 1367-1381.

Hernandez, A.E., Martinez, A. \& Kohnert, K. (2000). In search of the language switch: An fMRI study of picture naming in Spanish-English bilinguals. Brain and Language, 73, 421-431.

Hernandez, A.E., Dapretto, M., Mazziotta, J. \& Bookheimer, S. (2001). Language switching and language representation in Spanish-English bilinguals: An fMRI study. NeuroImage, 14, $510-520$. 
Hernandez, A.E., Hofmann, J. \& Kotz, S.A. (2007). Age of acquisition modulates neural activity for both regular and irregular syntactic functions. NeuroImage, 36, 912-923.

Humphreys, G.W., Riddoch, M.J. \& Quinlan, P.T. (1988). Cascade processes in picture identification. Cognitive Neuropsychology, 5, 67-103.

Illes, J., Francis, W.S., Desmond, J.E., Gabrieli, J.D., Glover, G.H., Poldrack, R., Lee, C.J. \& Wagner, A.D. (1999). Convergent cortical representation of semantic processing in bilinguals. Brain and Language, 70, 347-63.

Indefrey, P. \& Levelt, W.J.M. (2000). The neural correlates of language production. In Gazzaniga M. (Ed.), The New Cognitive Neurosciences (pp. 845-865). Cambridge, MA: MIT Press.

Indefrey, P. (2006). A meta-analysis of hemodynamic studies on first and second language processing: Which suggested differences can we trust and what do they mean? Language Learning, 56, 279-304.

Kiefer, M., Ahlegian, M. \& Spitzer, M. (2005a). Working memory capacity, indirect semantic priming and Stroop interference: Pattern of interindividual prefrontal performance differences in healthy volunteers. Neuropsychology, 19, 332-344.

Kiefer, M. (2005b). Repetition priming modulates category-related effects on event-related potentials: Further evidence for multiple cortical semantic systems. Journal of Cognitive Neuroscience, 17,199-211.

Kim, K.H., Relkin, N.R., Lee, K.M. \& Hirsch, J. (1997). Distinct cortical areas associated with native and second languages. Nature, 388, 171-174.

Kotz, S.A. (2009). A critical review of ERP and fMRI evidence on L2 syntactic processing. Brain and Language, 109, 68-74. 
Levelt, W.J.M., Roelofs, A. \& Meyer, A.S. (1999). A theory of lexical access in speech production. Behavioral and Brain Sciences, 22, 1-38; discussion, 38-75.

Nobre, A.C. \& McCarthy, G. (1995). Language-related field potentials in the anterior-medial temporal lobe: II. Effects of word type and semantic priming. Journal of Neuroscience, $15,1090-1098$.

Norman, D.A. \& Shallice, T. (1986). Attention to action: Willed and automatic control of behavior. In Davidson, R.J., Schwartz, G.E. \& Shapiro, D. (Eds.), Consciousness and self-regulation (pp. 1-18). New York: Plenum Press,.

Oldfield, R. (1971). The assessment and analysis of handedness: The Edinburgh Inventory. Neuropsychologia, 9, 97-113.

Paulesu, E., Frith, C.D. \& Frackowiak, R.S. (1993). The neural correlates of the verbal component of working memory. Nature, 362, 342-5.

Perani, D., Paulesu, E., Sebastian-Gallés, N., Dupoux, E., Dehaene, D., Bettinardi, V., Cappa, S., Fazio, F. \& Mehler, J. (1998). The bilingual brain: Proficiency and age of acquisition of the second language. Brain, 121, 1841-1852.

Perani, D. \& Abutalebi, J. (2005). The neural basis of first and second language processing. Current Opinion in Neurobiology, 15, 202-6.

Petersen, S.E., Fox, P.T., Posner, M.I., Mintun, M. \& Raichle, M.E. (1988). Positron emission tomographic studies of the cortical anatomy of single-word processing. Nature, 331, 5859.

Posner, M.I. \& DiGirolamo, G.J. (1998). Executive attention: Conflict, target detection and cognitive control. In Parasuman, R. (Ed.), The attentive brain (pp. 401-423). Cambridge, MA: MIT Press.. 
Ranganath, C., Heller, A.S. \& Wilding, E.L. (2007). Dissociable correlates of two classes of retrieval processing in prefrontal cortex. NeuroImage, 35, 1663-1673.

Rodriguez-Fornells, A., Van der Lugt, A., Rotte, M., Britti, B., Heinze, H.J. \& Münte, T.F. (2005). Second language interferes with word production in fluent bilinguals: brain potential and functional imaging evidence. Journal of Cognitive Neuroscience, 17, 42233.

Rubia, K., Smith, A. B., Brammer, M. J., \& Taylor, E. (2003). Right inferior prefrontal cortex mediates response inhibition while mesial prefrontal cortex is responsible for error detection. NeurImage, 20, 351-358.

Schafer, R. J. \& Constable, T. (2009). Modulation of functional connectivity with the syntactic and semantic demands of a Noun Phrase Formation Task: A possible role for the Default Network. NeuroImage, 46, 882-890.

Silveri, M.C. \& Misciagna, S. (2000). Language, memory, and the cerebellum. Journal of Neuroimaging, 13, 129-143.

Snodgrass, J.G. \& Vanderwart, M. (1980). A Standardized Set of 260 Pictures: Norms for Name Agreement, Image Agreement, Familiarity, and Visual Complexity. Journal of Experimental Psychology, 6, 174-215.

Suh, S., Yoon, H.W., Lee, S., Chung, J.Y., Cho, Z.H. \& Park, H. (2007). Effects of syntactic complexity in L1 and L2; an fMRI study of Korean-English bilinguals. Brain Research, 1136(1), 178-89.

Tulving, E. (1999). On the uniqueness of episodic memory. In: Nilsson LG, Markowitsch HJ (Eds.), Cognitive Neuroscience of Memory (pp. 11-42). Göttingen: Hogrefe and Huber,. 
Vallesi, A. \& Shallice, T. (2006). Prefrontal involvement in source memory: an electrophysiological investigation of accounts concerning confidence and accuracy. Brain Research, 1124, 111-25.

Vandenberghe, R., Price, C., Wise, R., Josephs, O. \& Frackowiak, R.S.J. (1996). Functional anatomy of a common semantic system for words and pictures. Nature, 383, 254-256.

Vingerhoets, G., Van Borsel, J., Tesink, C., Van den Noort, M., Deblaere, K., Seurinck, R., Vandemaele, P. \& Achten, E. (2003). Multilingualism: an fMRI study. NeuroImage, 20, 2181-2196.

Wise, R., Chollet, F., Hadar, U., Friston, K., Hoffner, E. \& Frackowiak, R. (1991). Distribution of cortical neural networks involved in word comprehension and word retrieval. Brain, 114, 1803-17.

Yetkin, O., Yetkin, Z., Haughton, V. \& Cox, R.W. (1996). Use of functional MR to map language in multilingual volunteers. American Journal of Neuroradiology, 17, 473-477.

Yokoyama, S., Okamoto, H., Miyamoto, T., Yoshimoto, K., Kim, J., Iwata, K., Jeong, H., Uchida, S., Ikuta, N., Sassa, Y., Nakamura, W., Horie, K., Sato, S. \& Kawashima, R. (2006). Cortical activation in the processing of passive sentences in L1 and L2: An fMRI study. NeuroImage, 30, 570-9. 


\section{Figure captions}

Figure 1: Geographical location of the Ladin speaking valleys (colored areas) in the Dolomites mountain range, South Tyrol, Italy.

Figure 2: Functional brain activation in multilingual word production during a picture naming task. Illustration of the main effect of word production (contrasted with the fixation baseline condition) collapsed across languages (Ladin, Italian and English). Functional group activation maps are displayed at $\mathrm{p}<0.001$ (corrected) and projected on the surface of the T1 MNI reference brain.

Figure 3: Functional brain activation related to high language proficiency in the right prefrontal cortex. Activation maps are overlaid on the T1 MNI reference brain. (A) Stronger activity to the highly fluent first language Ladin in comparison to the less fluent fourth language English (p < .001, uncorrected). (B) Stronger activity to the highly fluent second language Italian in comparison to English ( $\mathrm{p}<.001$, uncorrected). (C) Commonalities in activation differences pertaining to the two functional contrasts comparing the highly fluent languages Ladin and Italian with the less fluent language English $(\mathrm{p}<.005$, uncorrected). (D) Correlation analysis relating naming accuracy to the MR signal across the entire brain. Left panel: A significant correlation was observed in right dorsolateral prefrontal cortex in BA 46 ( $p<.001$, uncorrected) for English. When slightly lowering the statistical threshold $(\mathrm{p}<.005)$, a significant correlation in this region was also found for Italian (not shown in this panel). Right panel: Plot showing the 


\section{Tables}

Table 1: Functional brain activation to languages at different levels of proficiency. The significance level for each contrast was $p<.001$, uncorrected.

\begin{tabular}{|c|c|c|c|c|c|c|c|}
\hline \multicolumn{3}{|c|}{ Anatomical description } & \multirow[t]{2}{*}{ No. of voxels } & \multirow[t]{2}{*}{ Z score } & \multicolumn{3}{|c|}{ MNI } \\
\hline & $\mathrm{Hem}$ & $\mathrm{BA}$ & & & $\mathrm{x}$ & $\mathrm{y}$ & Z \\
\hline \multicolumn{8}{|c|}{ Ladin > English } \\
\hline SFG & $\mathrm{R}$ & 11 & 16 & 3.72 & 20 & 36 & -20 \\
\hline MFG & $\mathrm{R}$ & $46 / 10$ & 19 & 3.57 & 28 & 56 & 14 \\
\hline \multicolumn{8}{|c|}{ Italian > English } \\
\hline Insula & $\mathrm{R}$ & 47 & 21 & 3.49 & 34 & 16 & 0 \\
\hline MFG & $\mathrm{R}$ & 47 & 37 & 4.09 & 46 & 42 & -8 \\
\hline MFG & $\mathrm{R}$ & 46 & 67 & 3.80 & 42 & 48 & 8 \\
\hline \multicolumn{8}{|c|}{ English > Ladin } \\
\hline \multirow[t]{2}{*}{ Cerebellum } & $\mathrm{L}$ & - & 32 & 3.73 & -20 & -68 & -20 \\
\hline & $\mathrm{R}$ & - & 29 & 3.69 & 24 & -76 & -50 \\
\hline IFG & $\mathrm{L}$ & $44 / 6$ & 14 & 3.52 & -58 & 10 & 32 \\
\hline \multicolumn{8}{|c|}{ English > Italian } \\
\hline Cerebellum & $\mathrm{L}$ & - & 23 & 3.95 & -20 & -66 & -34 \\
\hline \multicolumn{8}{|c|}{ Italian > Ladin } \\
\hline MTG & $\mathrm{R}$ & 39 & 37 & 4.07 & 46 & -70 & 14 \\
\hline
\end{tabular}




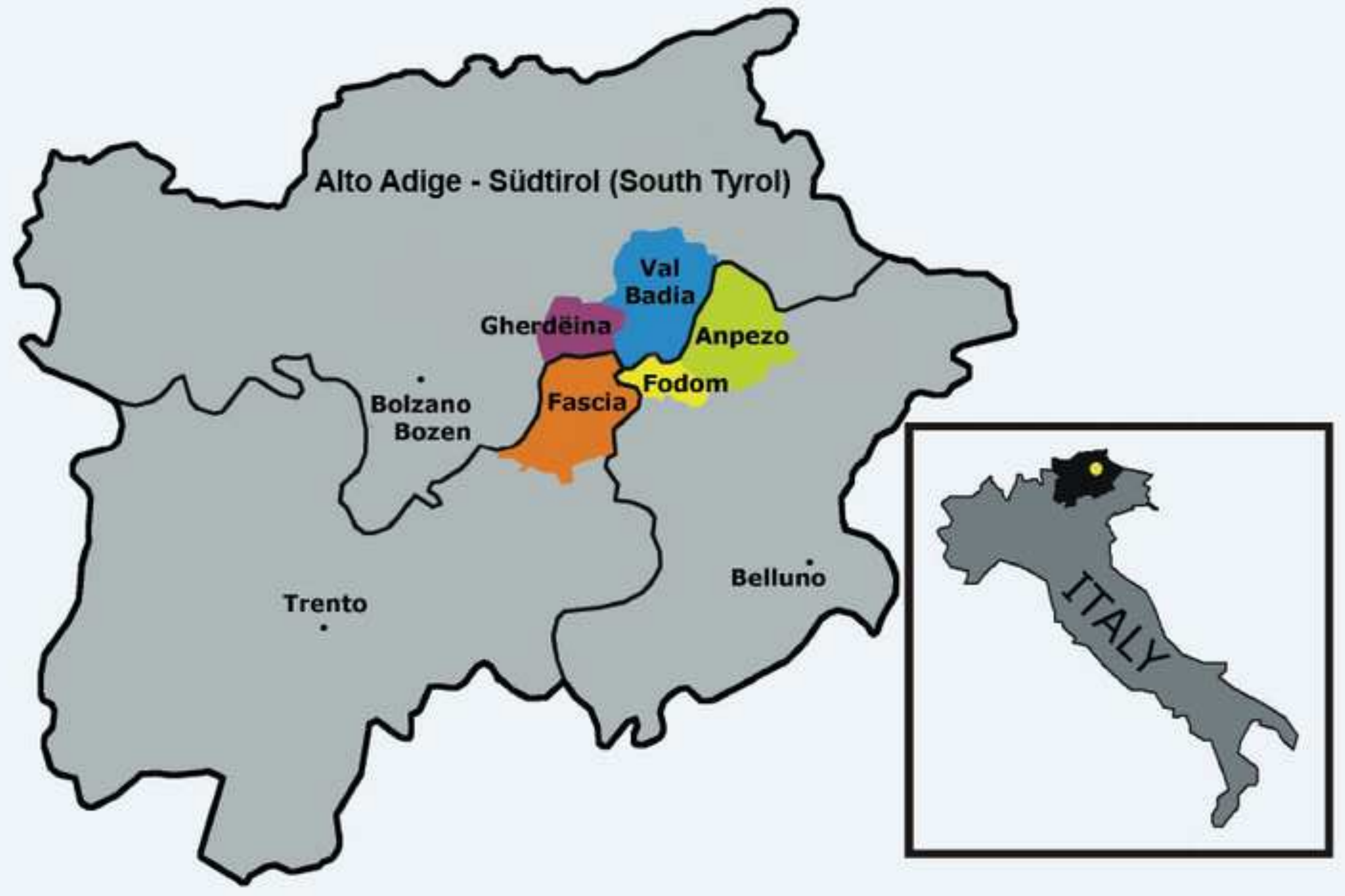


Figure 2

Click here to download high resolution image

\section{Main Effect: Languages}
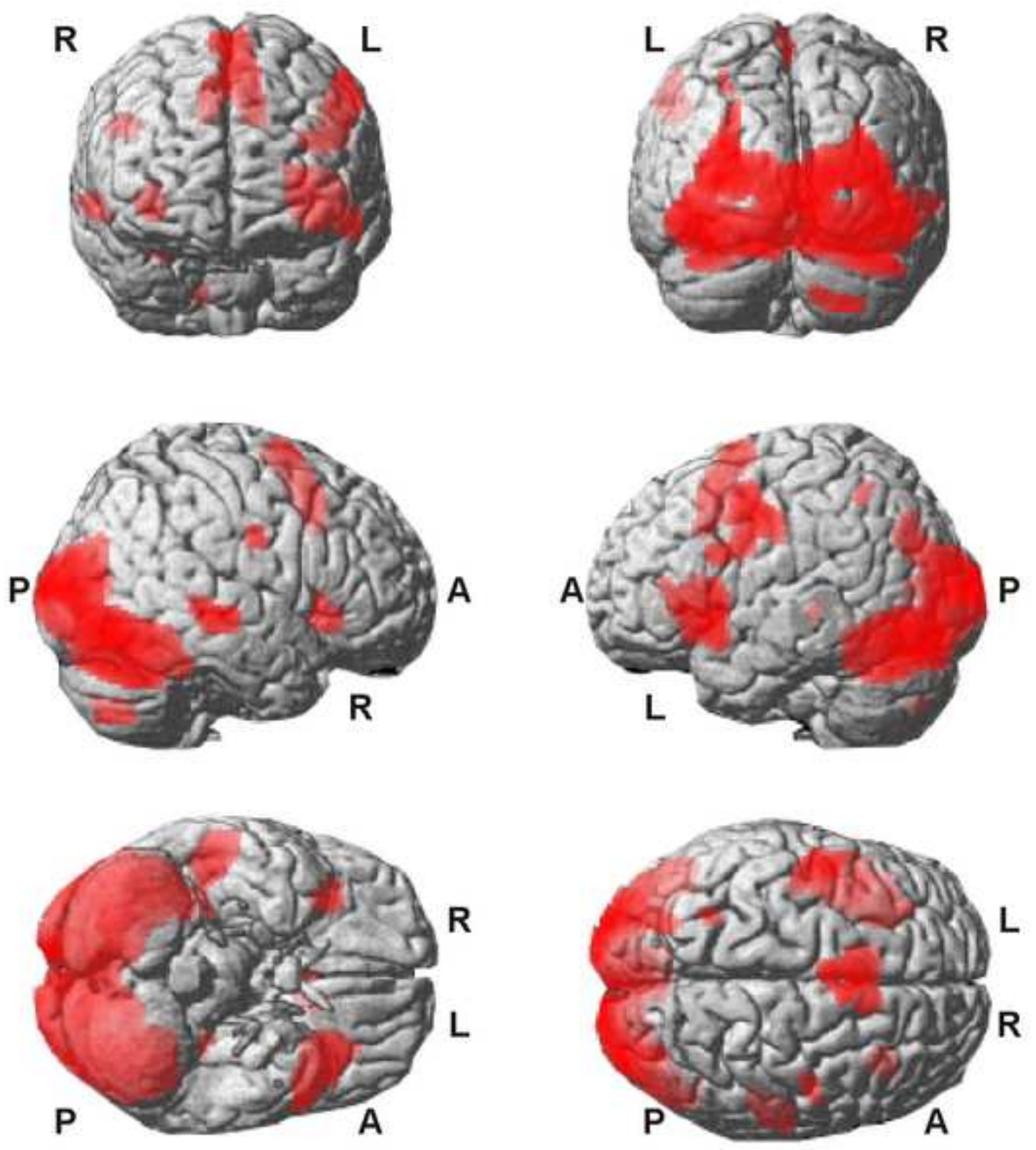
Figure 3

Click here to download high resolution image

A

Italian > English
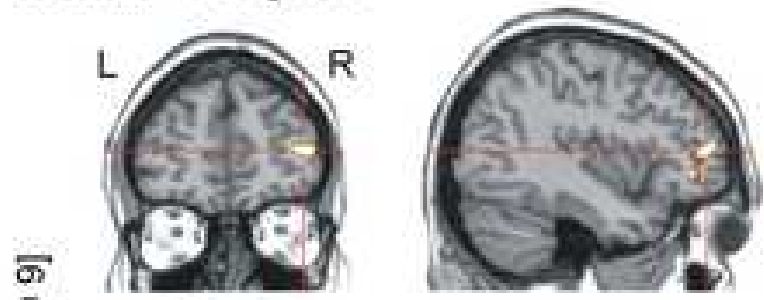

守

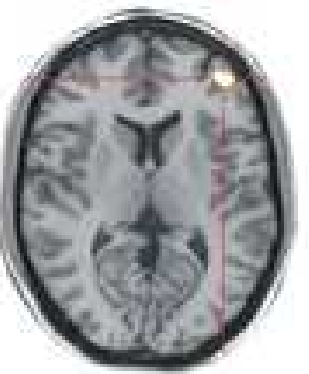

Middle frontal $\mathrm{g}$.

(BA 46)

B

Ladin > English
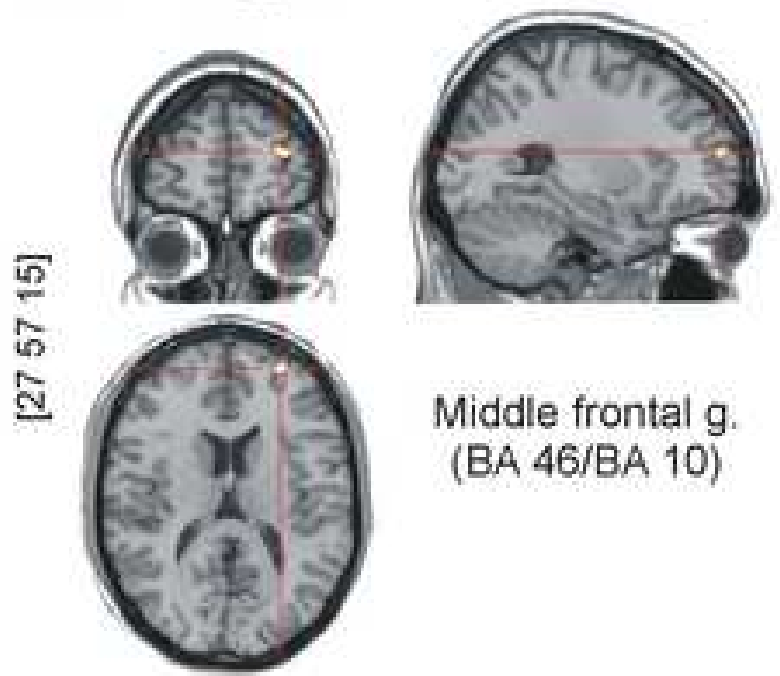

Middle frontal $\mathrm{g}$.

(BA 46/BA 10)
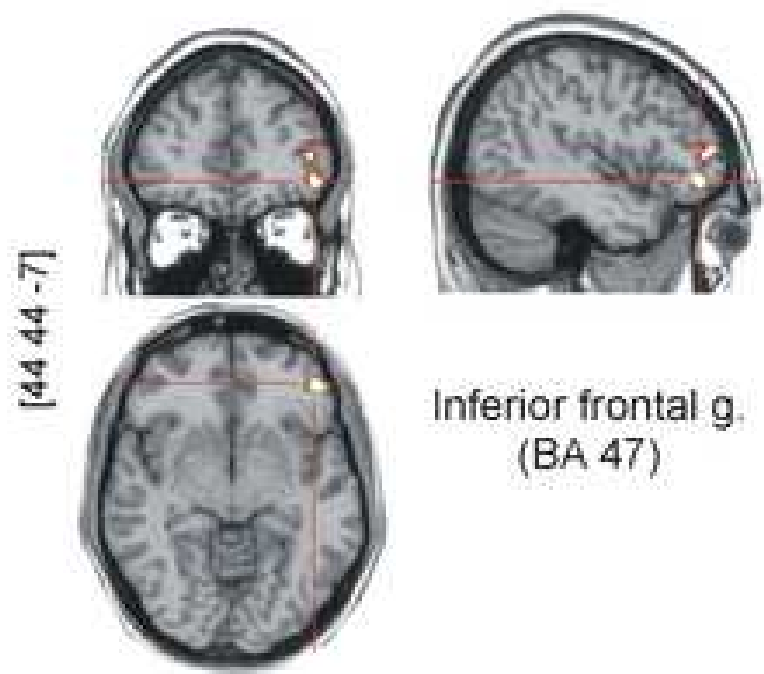

Inferior frontal $\mathrm{g}$.

(BA 47)

C

Conjunction $(I>E \cap L>E)$
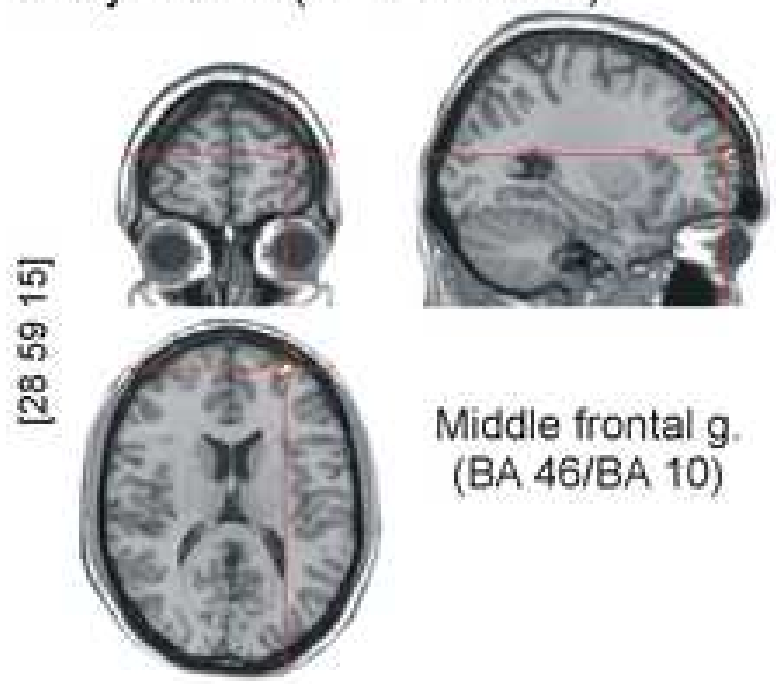

Middle frontal $\mathrm{g}$.

(BA 46/BA 10)

Regression ( $\mathrm{E} \times$ naming acuracy)
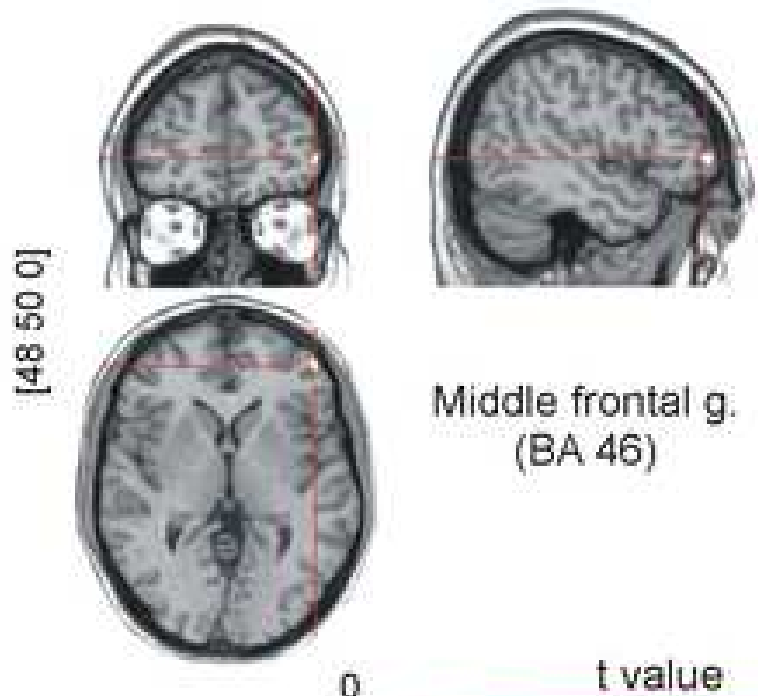

Middle frontal $\mathrm{g}$.

(BA 46)

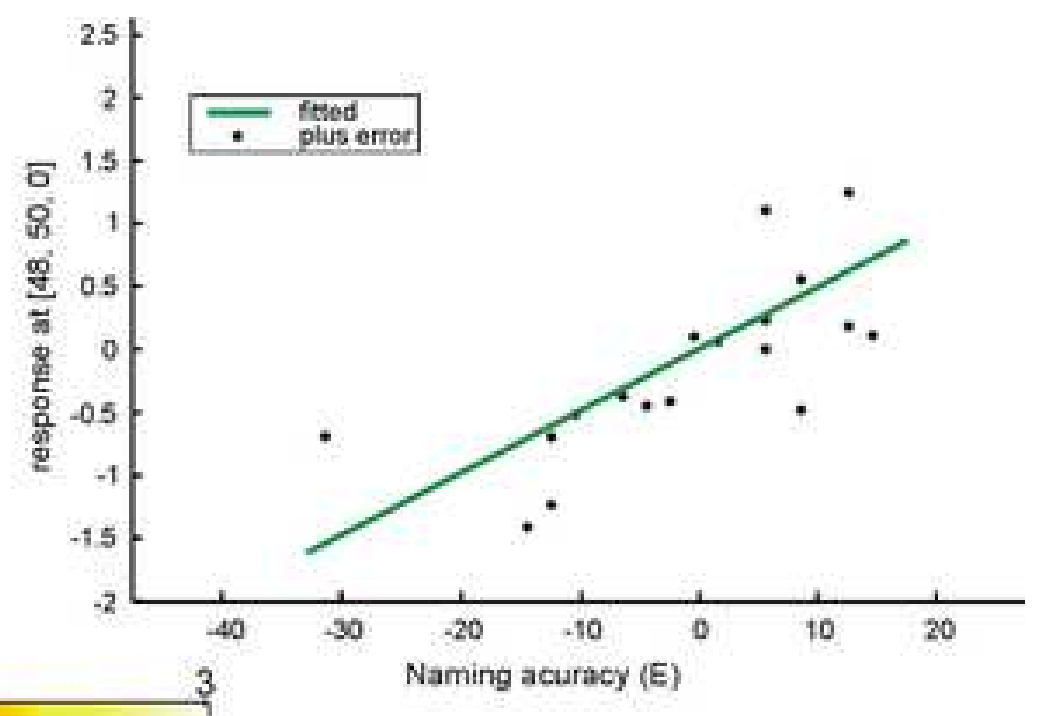

t value 

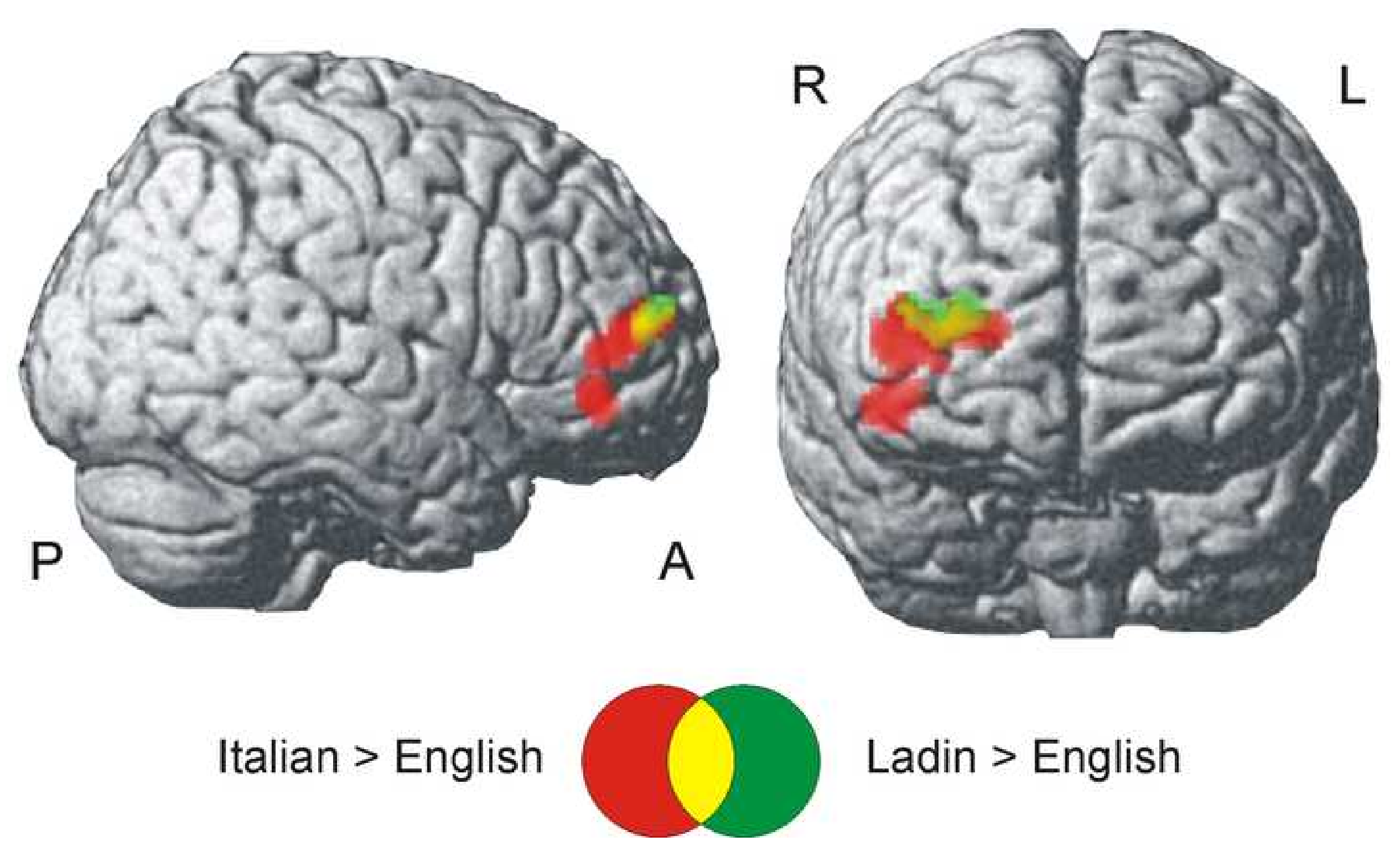

Italian > English

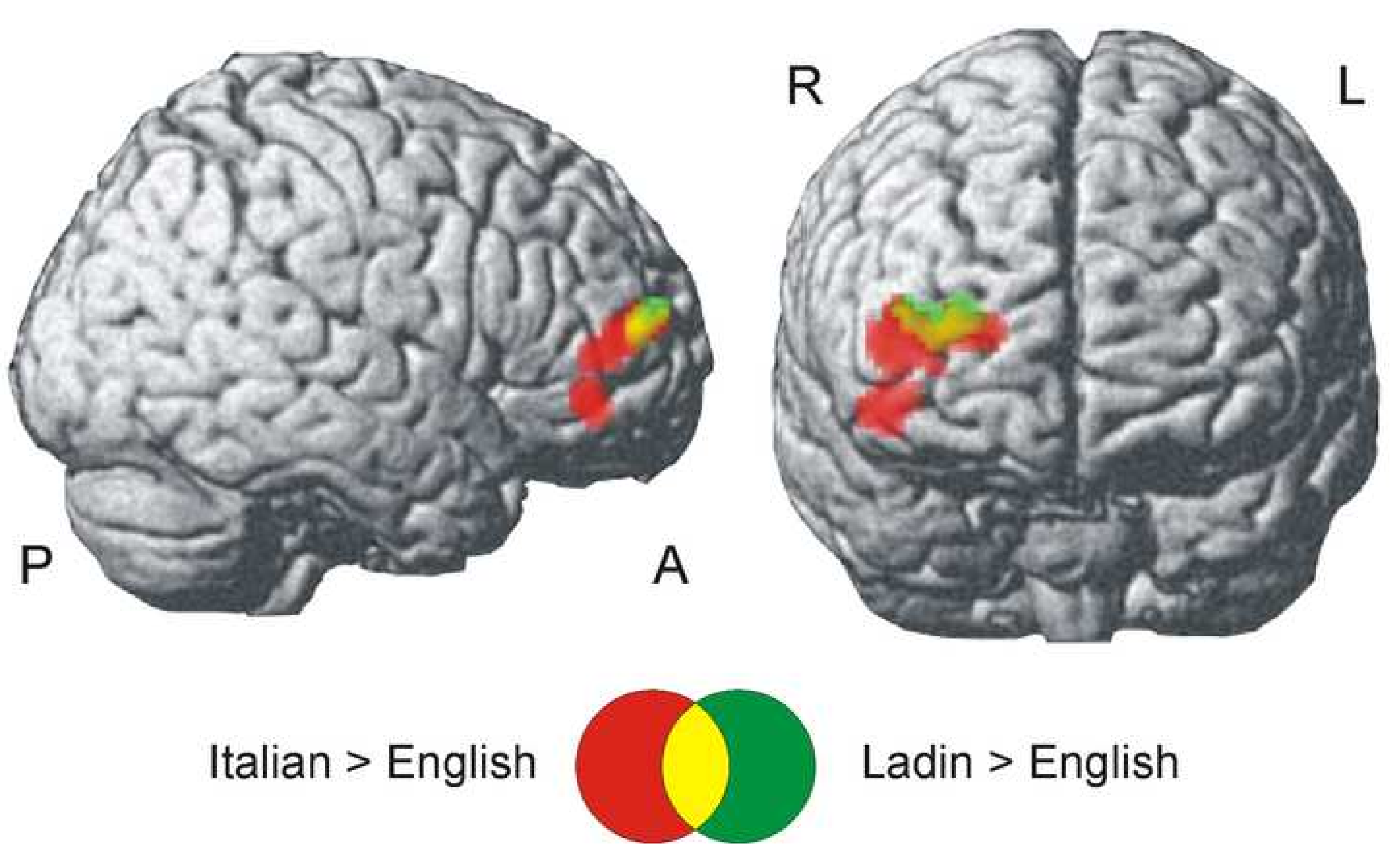

Ladin > English

.




\section{English Italian Ladin}

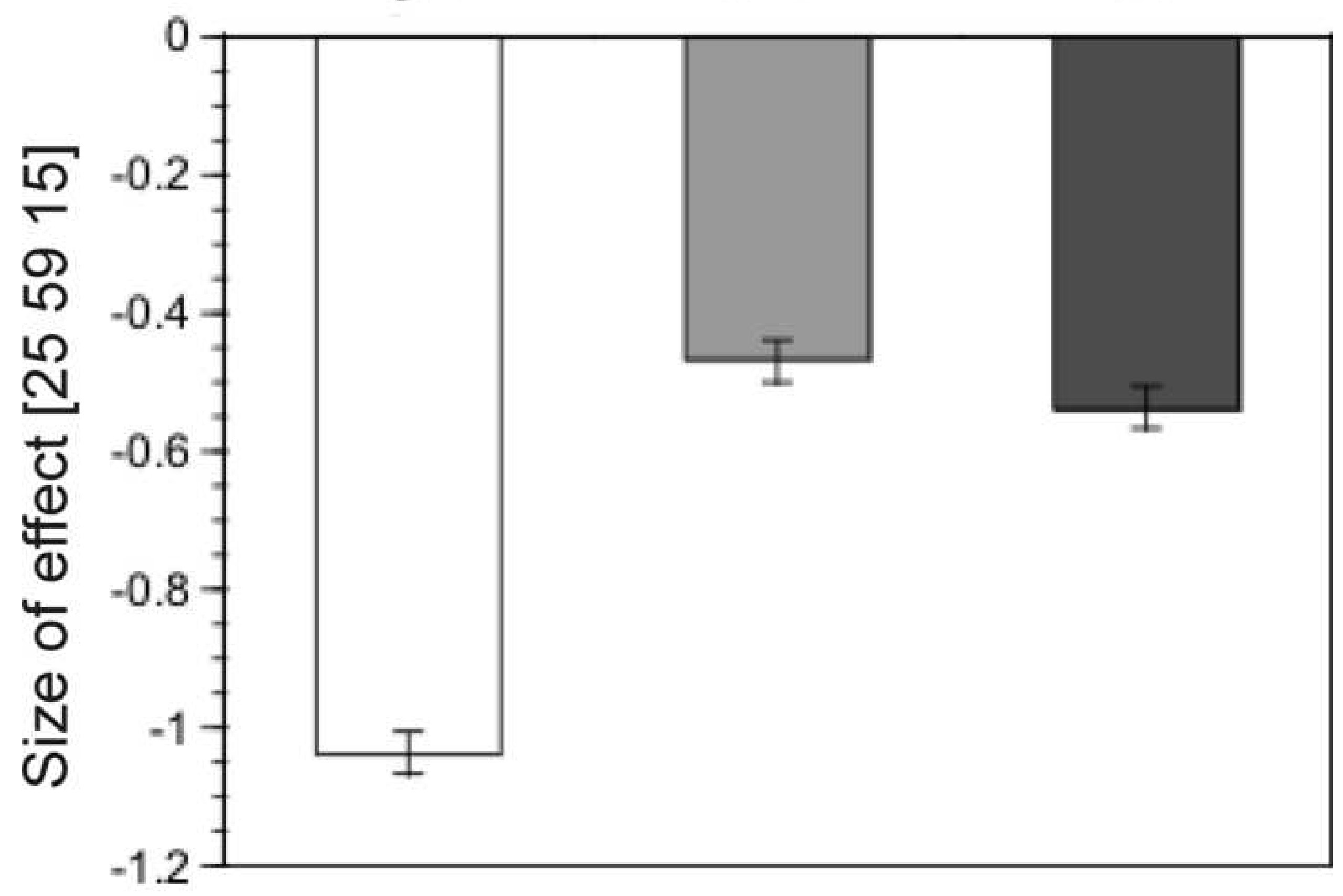




\section{English > Ladin}
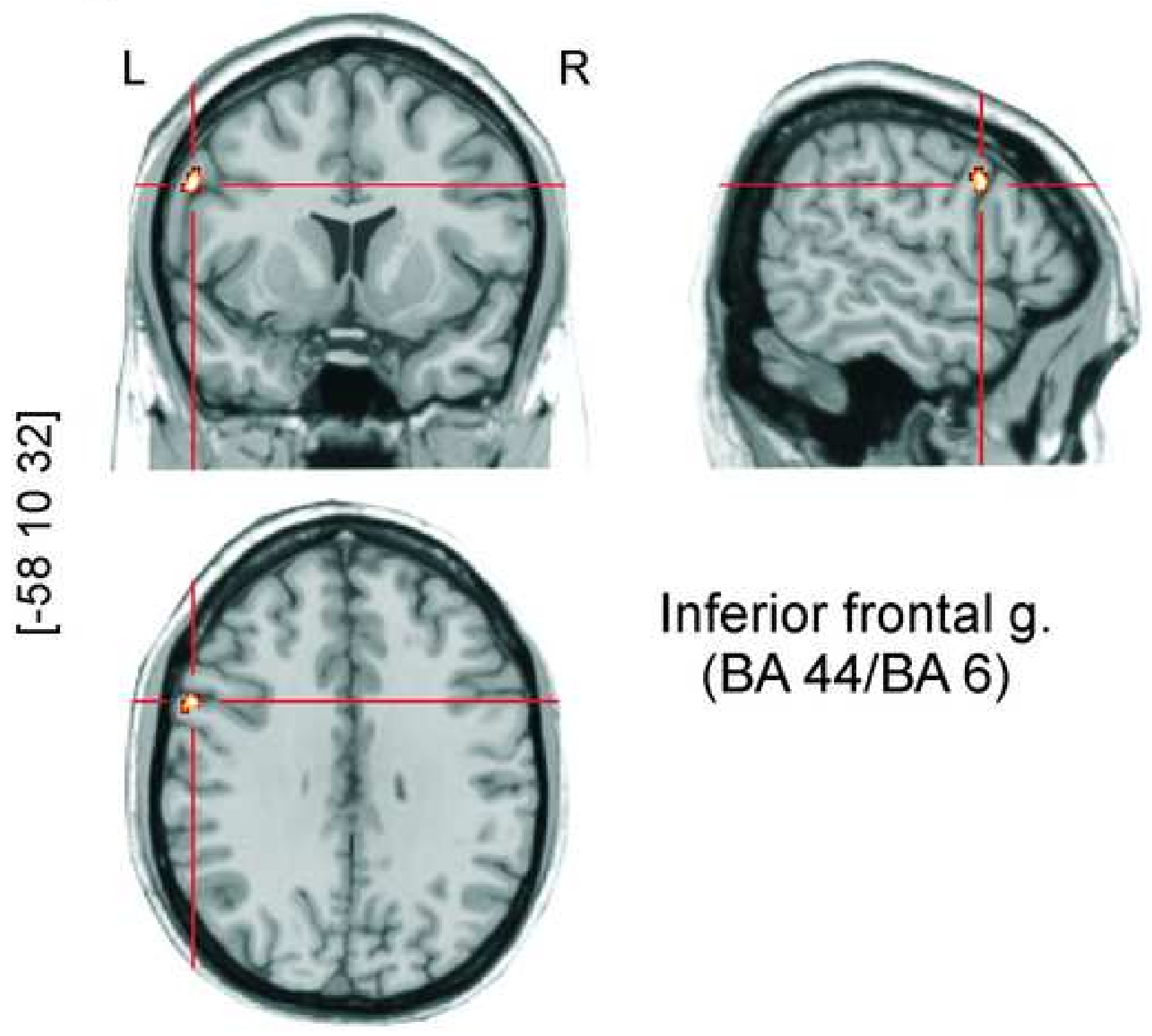

\section{Inferior frontal $\mathrm{g}$. (BA 44/BA 6)}

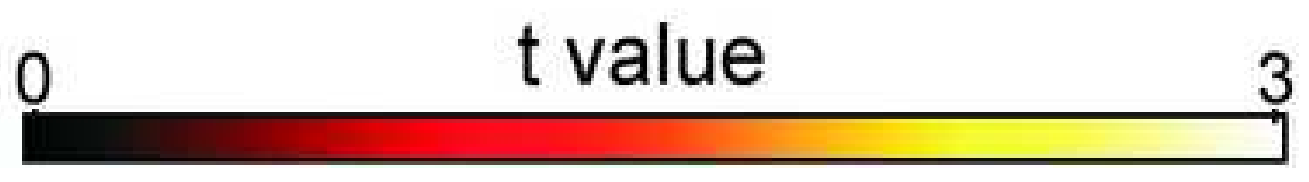


Supplementary Material
Click here to download Supplementary Material: Kiefer_SupplementaryMaterial_rev.doc

pplementary Material: Kiefer_SupplementaryMaterial_rev.doc

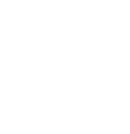

(20)

(n)

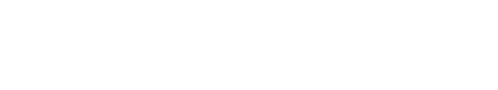
(1) (1) (1)

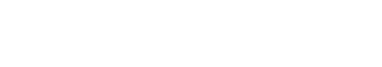
. (1) (1) (1) (1) (1) (1) (1) (1) (1) (1) (1) (1) (1)

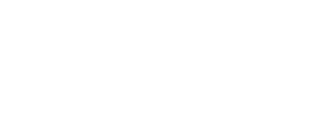
(1)

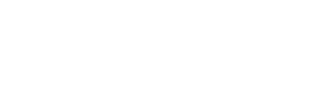

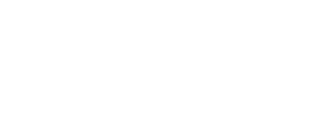

